\title{
A BR-101 e a litoralização do Estado de Santa Catarina
}

\author{
Izidro Tomaz Nunes* \\ João Rogério Sanson **
}

\begin{abstract}
Resumo
Verifica-se o possível impacto da rodovia BR-101, inaugurada em 1971, sobre a movimentação populacional do interior para o litoral no Estado de Santa Catarina. Os Censos compreendidos na análise são os de 1950 a 1991. Como diferencial metodológico, dividiu-se o Estado em duas grandes regiões, o Litoral e o Interior, com homogeneização desse espaço entre os Censos. Como resultados principais, verificou-se que, entre 1950 e 1970, o Litoral, na verdade, vinha perdendo participação, atingindo ao redor de 50\% da população em 1970, para depois ganhar participação até atingir 57\% em 1991. Esse resultado, já constatado para décadas recentes, mas agora com uma medição mais precisa até 1991, corrobora a hipótese de que a inauguração da BR-101 está positivamente correlacionada com esse movimento migratório. A imigração total para as duas regiões teve ritmos de aumento não muito diferentes, acompanhando de perto o ritmo de imigração interna do país como um todo. Os imigrantes do Litoral em sua maioria vieram de Santa Catarina, em proporção decrescente a partir de 1980. Os imigrantes de outros Estados vieram principalmente do Paraná e do Rio Grande do Sul, embora não tenha sido possível discriminar para que região de Santa Catarina eles foram. Esse resultado reforça o que se observou para a população total, mostrando que a rodovia deve ter facilitado a migração. Quanto às taxas de urbanização em cada uma das duas regiões, houve pouco impacto diferenciado entre elas.
\end{abstract}

Palavras-chave: migração; rodovia BR-101; Santa Catarina.

\section{The BR-101 highway and migration to the littoral of the Santa Catarina State, Brazil}

\begin{abstract}
We verify the likely effect of the coastal BR-101 highway on migration from the interior to the littoral of the Santa Catarina State, Brazil. We cover the censuses from 1950 to 1991. As a methodological differential, we divided the State into two large regions, the Littoral and the Interior, equalizing them along time. As our main result, we found that between 1950 and 1970, the Littoral was in fact losing its share, reaching around 50\% of the population in 1970. In the two following censuses, the Littoral then gained participation until reaching $57 \%$ in 1991. This tendency, already verified for recent decades, but now with a more accurate measurement up to 1991, corroborates the hypothesis that the inauguration of BR-101 is positively correlated with this migratory movement. Total immigration into the two regions had not very different growth rates, following closely the pace of internal immigration of the country as a whole. The immigrants to the Littoral were mostly from Santa Catarina, but their proportion was decreasing from the 1980 Census on. Immigrants from other states mainly from Paraná and Rio Grande do Sul states, although we were unable to discriminate which region of Santa Catarina they moved into. This result reinforces what was observed for the total population, showing that the highway might have made it easier to migrate. As to the effect on the urbanization rates of each area, there was a slight difference between them.
\end{abstract}

Key words: migration; BR-101 highway; Santa Catarina State

JEL Classification: J61, O18, R11

\footnotetext{
* Bacharel em Economia, Caixa Econômica Federal. E-mail: izidrotn@gmail.com

** Economista e professor da UFSC.E-mail: j.sanson@ufsc.br
} 


\section{Introdução}

No período posterior ao Censo Demográfico de 1950, foram observadas intensas alterações na distribuição espacial da população em Santa Catarina, com destaque para a complexidade e a diversificação dos deslocamentos populacionais do campo para os centros urbanos do litoral. Há boas razões para supor que esses deslocamentos foram motivados, sobretudo, pela construção da rodovia BR-101. Uma grande rodovia como essa reforça e transforma atividades econômicas já existentes, além de atrair novas atividades por conta da redução de custos de transporte.

A política de integrar os diversos polos produtivos espalhados pelo país induziu, em 1964, o Plano Nacional de Viação, na forma da Lei 4.592, incluindo a BR-101. Como rodovia longitudinal, acompanhava o litoral do Brasil e buscava alcançar 4.080 quilômetros de extensão, tendo como extremos os Estados do Rio Grande do Norte e do Rio Grande do Sul (BRASIL, 1964). Ela teve desde sua inauguração significativo impacto sobre a ampliação da atividade econômica em toda sua extensão (IBGE, 2011). Contudo, em contraste com vários dos demais Estados brasileiros ao longo da rodovia, em que suas capitais são as cidades onde se concentra a população e a atividade econômica, o Estado de Santa Catarina tinha e ainda tem sua população distribuída entre muitas cidades médias, o que inclui a sua capital. Algumas dessas cidades médias importantes estão no interior do Estado.

No trecho catarinense, a rodovia BR-101 foi construída em várias etapas e oficialmente inaugurada e liberada para o tráfego de veículos somente em 1971 (VASQUES, 2002). Diariamente, ao longo dos 465,9 quilômetros de pavimentação que contemplam o litoral catarinense, grande parte da produção industrial e agropecuária do Estado é escoada, e um fluxo significativo de pessoas é deslocado, utilizando-a também como a principal via turística para a faixa litorânea.

O impacto de uma grande rodovia como a BR-101 ocorre por múltiplos canais e em diferentes horizontes temporais. Pode ser maior num espaço como o de uma grande região, associada a grandes corredores de transporte, em comparação com o espaço mais restrito de uma região menor como o de apenas uma faixa de um Estado. Uma das razões para isso são as externalidades de rede decorrentes da integração de atividades dos diferentes setores de uma economia. Seu impacto é também diferenciado de acordo com a intensidade do uso dos serviços de transporte e de seus custos para diferentes setores econômicos. Setores que dependem da produtividade do setor de transporte, traduzida em economia de tempo e de custos, respondem melhor no longo prazo, em termos de crescimento. Mercados locais antes protegidos pelo alto custo de transporte encolhem, afetando os respectivos setores. As pesquisas empíricas, contudo, 
têm como consenso apenas que a resposta do produto de uma determinada região é baixa no curto prazo, aumentando no longo prazo, mas sem consenso quanto aos valores das respectivas elasticidades. As migrações populacionais reagem ao aumento de oportunidades de emprego, o que ocorre com mais facilidade no setor de serviços, nas regiões de destino mais afetadas pela nova infraestrutura. ${ }^{1}$

A expansão das atividades econômicas nas cidades catarinense às margens da BR-101 permitiu que a ocupação espacial se desenvolvesse e se concentrasse nos principais centros urbanos influenciados pela construção da via. Isso definiu novas configurações para o processo de ocupação espacial dessas regiões do Estado. O arranjo espacial das atividades econômicas, ao longo do perímetro da rodovia, motivado pelos fluxos de investimentos, presumivelmente tornou-se o principal incentivo às migrações internas, sobretudo do campo para a cidade. Novas oportunidades de empregos e expectativas de diferenciais de renda entre regiões representam elementos fundamentais na decisão de migrar. No caso de Santa Catarina, isso levou a uma forte concentração da população no litoral, associado assim a setores econômicos importantes das principais cidades, como no caso de Joinville, Blumenau e Jaraguá do Sul, cidades industriais, e Blumenau e Florianópolis, cidades principalmente turísticas. ${ }^{2}$

Vários estudos têm abordado a questão do movimento migratório para o litoral catarinense, dos quais mencionam-se dois. O primeiro deles é Mioto (2008), que discute detalhadamente o conceito de saldo migratório e o aplica para os municípios catarinenses, agrupados segundo as Secretarias de Desenvolvimento Regional. Usa de forma intensiva os dados de uma contagem populacional de 2007, mas também os Censos de 1991 e 2000. Conclui ter havido forte migração do interior para o litoral, com significativa metropolização da capital do Estado.

Outro estudo, o de Craice e Pezzo (2015), tem abordagem puramente demográfica, com foco na composição por sexo e idade, segundo cinco regiões e as dez principais cidades catarinenses. Com dados dos Censos de 1991 a 2010, corrobora a hipótese de litoralização com base nas taxas de crescimento populacional do período.

Além de fatores de expulsão da população rural do interior, há também a própria tendência de urbanização do país como um todo, na medida em que a economia se moderniza e torna vantajosa a fixação das populações nas cidades. Ao mesmo tempo, há evidências de que a partir dos anos 1980 tem havido desconcentração da atividade econômica do Sudeste do país,

\footnotetext{
${ }^{1}$ Resenhas recentes dos estudos empíricos acerca dos efeitos econômicos da infraestrutura de transporte, abordando vários desses pontos, são: Pereira e Andraz (2013), Deng (2013) e Elburz, Nijkamp e Pels (2017).

${ }^{2}$ Uma linha de pesquisa de um dos autores deste artigo resultou em nove trabalhos de conclusão de curso de graduação sobre o impacto da BR-101 no crescimento das principais cidades ao longo do litoral e algumas do interior de Santa Catarina.
} 
especialmente de São Paulo. Há dúvidas se isso ocorreu para outras regiões do país ou se apenas dentro do próprio Estado (CUNHA; BAENINGER, 2005).

O presente estudo pretende verificar a hipótese de que a construção da BR-101 teve forte influência na migração para o litoral de SC. Como a estrada foi inaugurada no início dos anos 1970 e já houve tempo para que seus efeitos de longo prazo se fizessem sentir, a pergunta é se a litoralização já ocorria naquele período ou se foi tendência posterior à inauguração da rodovia. Outro ponto a conferir é se a litoralização ocorreu com a predominância de imigrantes do interior do Estado. Pelo fato de a rodovia servir as principais cidades do litoral, espera-se, além disso, um aumento relativo no grau de urbanização do litoral.

Na próxima seção, apresenta-se a metodologia utilizada. Ela envolve a definição de duas regiões homogêneas no Estado: Litoral e Interior. Será com tal divisão do espaço catarinense, sob controle ao longo de 40 anos, que a hipótese será testada. Na seção posterior, estudam-se os dados referentes à litoralização. Na seção seguinte, busca-se verificar a hipótese de que a litoralização teria ocorrido principalmente pela migração de moradores do Interior. Por fim, procura-se verificar também se a rodovia influenciou a trajetória da estrutura urbano-rural em cada uma das duas regiões.

\section{Procedimentos metodológicos}

Para a consecução dos objetivos propostos neste trabalho, dividiu-se o Estado de Santa Catarina em duas grandes regiões, a saber, as Zonas ou Microrregiões do Litoral e as Zonas ou Microrregiões do Interior, ${ }^{3}$ de acordo com o limite das Zonas Fisiográficas ou Microrregiões estabelecido pelo IBGE, conforme ilustrado na Figura 1.

\footnotetext{
3 As Zonas ou Microrregiões do Litoral ou do Interior são referidas no texto e nas ilustrações, na maioria das vezes, apenas como Litoral ou Interior.
} 
Figura 1 - Divisão do Estado de Santa Catarina em Zonas ou Microrregiões do Litoral e Zonas ou Microrregiões do Interior

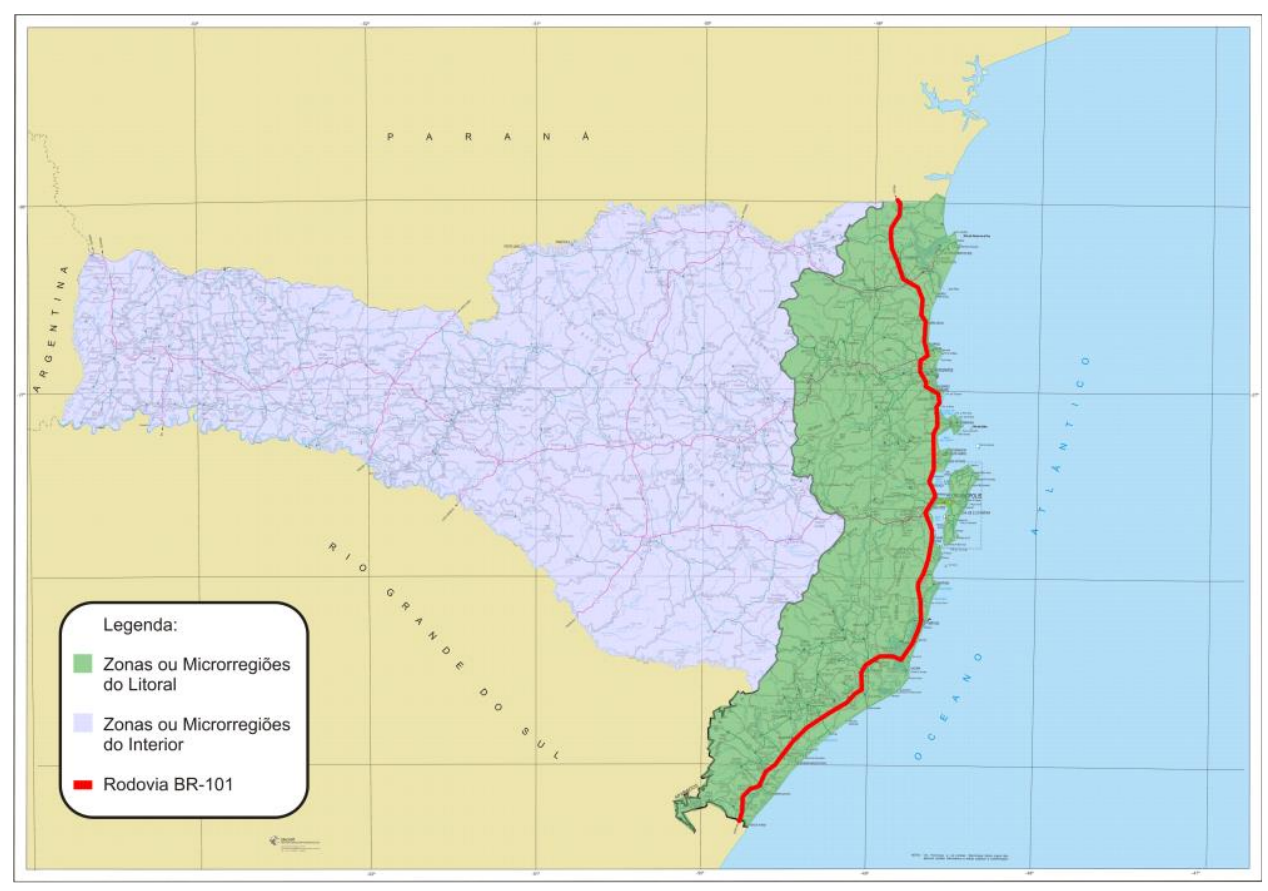

Fonte: BRASIL (2002), com adaptação

Diante da necessidade de obter-se uma mesma área representativa entre os anos de 1950 e 1991, utilizou-se a Divisão Regional do Estado de Santa Catarina de 7 de julho de 1955 (IBGE, 1958), para que fossem estabelecidas as Zonas ou Microrregiões do Litoral e as Zonas ou Microrregiões do Interior. Esse período de 40 anos, portanto, considera um intervalo de duas décadas anteriores e posteriores à inauguração da rodovia.

O Quadro 1 apresenta as Zonas Fisiográficas ou Microrregiões que compõem cada uma das regiões do período analisado. O agrupamento foi realizado de forma a se obter uma faixa territorial, ao longo da rodovia BR-101, que refletisse sua área de influência mais próxima, respeitando-se a divisão por Zonas Fisiográficas ou Microrregiões, salvo eventuais ajustes que se fizeram necessários para se manter o limite das áreas a serem observadas entre os anos de 1950 e 1991.

Para o período de análise, notou-se a formação de várias novas microrregiões no Estado de Santa Catarina. Essas microrregiões sofreram muitas transformações, com a partição dos municípios existentes e com a incorporação de novas áreas (SANTA CATARINA, 1991), razão pela qual ajustes de controle para a manutenção das mesmas áreas em todos os censos foram necessários ao longo da linha divisória entre as duas regiões, Interior e Litoral. Isso evitou alterações populacionais entre elas apenas pelo fracionamento dos municípios. 
Quadro 1 - Composição das Zonas ou Microrregiões do Litoral e do Interior, segundo as Zonas Fisiográficas ou Microrregiões - 1950 a 1991

\begin{tabular}{|c|c|c|c|c|c|}
\hline \multirow{2}{*}{ Região } & \multicolumn{2}{|c|}{ Zonas Fisiográficas } & \multicolumn{3}{|c|}{ Microrregiões } \\
\hline & 1950 & 1960 & 1970 & 1980 & 1991 \\
\hline & $\begin{array}{l}\text {-Litoral de } \\
\text { São } \\
\text { Francisco } \\
\text { do Sul } \\
\text {-Bacia do } \\
\text { Itajaí } \\
\text {-Litoral de } \\
\text { Florianópo- } \\
\text { lis } \\
\text {-Litoral de } \\
\text { Laguna }\end{array}$ & $\begin{array}{l}\text {-Litoral de } \\
\text { São } \\
\text { Francisco } \\
\text {-Bacia do } \\
\text { Itajaí } \\
\text {-Florianópolis } \\
\text {-Laguna }\end{array}$ & $\begin{array}{l}\text {-Colonial de Joinville } \\
\text {-Litoral de Itajaí } \\
\text {-Colonial de } \\
\text { Blumenau } \\
\text {-Florianópolis } \\
\text {-Colonial Serrana } \\
\text { Catarinense } \\
\text {-Litoral de Laguna } \\
\text {-Carbonífera } \\
\text {-Litoral Sul } \\
\text { Catarinense } \\
\text {-Colonial do Sul } \\
\text { Catarinense }\end{array}$ & $\begin{array}{l}\text {-Colonial de } \\
\text { Joinville } \\
\text {-Litoral de Itajaí } \\
\text {-Colonial de } \\
\text { Blumenau } \\
\text {-Florianópolis } \\
\text {-Colonial Serrana } \\
\text { Catarinense } \\
\text {-Litoral de Laguna } \\
\text {-Carbonífera } \\
\text {-Litoral Sul } \\
\text { Catarinense } \\
\text {-Colonial do Sul } \\
\text { Catarinense } \\
\end{array}$ & $\begin{array}{l}\text {-Joinville } \\
\text {-Itajaí } \\
\text {-Blumenau } \\
\text {-Tijucas } \\
\text {-Florianópolis } \\
\text {-Tabuleiro } \\
\text {-Tubarão } \\
\text {-Criciúma } \\
\text {-Araranguá }\end{array}$ \\
\hline & $\begin{array}{l}\text { - Planalto de } \\
\text { Canoinhas } \\
\text {-Campos de } \\
\text { Lages } \\
\text { - Joaçaba } \\
\text { - Iguaçu }\end{array}$ & $\begin{array}{l}\text {-Canoinhas } \\
\text {-Campos de } \\
\text { Lages } \\
\text {-Rio do Peixe } \\
\text {-Oeste }\end{array}$ & $\begin{array}{l}\text {-Planalto de } \\
\text { Canoinhas } \\
\text {-Colonial do Itajaí do } \\
\text { Norte } \\
\text {-Colonial do Alto } \\
\text { Itajaí } \\
\text {-Campos de Lages } \\
\text {-Campos de } \\
\text { Curitibanos } \\
\text {-Colonial do Rio do } \\
\text { Peixe } \\
\text {-Colonial do Oeste } \\
\text { Catarinense }\end{array}$ & $\begin{array}{l}\text {-Planalto de } \\
\text { Canoinhas } \\
\text {-Colonial do Itajaí } \\
\text { do Norte } \\
\text {-Colonial do Alto } \\
\text { Itajaí } \\
\text {-Campos de Lages } \\
\text {-Campos de } \\
\text { Curitibanos } \\
\text {-Colonial do Rio do } \\
\text { Peixe } \\
\text {-Colonial do Oeste } \\
\text { Catarinense }\end{array}$ & $\begin{array}{l}\text {-São Bento do } \\
\text { Sul } \\
\text {-Canoinhas } \\
\text {-Rio do Sul } \\
\text {-Ituporanga } \\
\text {-Campos de } \\
\text { Lages } \\
\text {-Curitibanos } \\
\text {-Joaçaba } \\
\text {-Xanxerê } \\
\text {-Concórdia } \\
\text {-Chapecó } \\
\text {-São Miguel } \\
\text { D’Oeste }\end{array}$ \\
\hline
\end{tabular}

Fonte: Adaptado de IBGE, Censos Demográficos de 1950, 1960, 1970, 1980 e 1991

Segundo o IBGE, Santa Catarina tinha 52 municípios em 1950, passando para $102 \mathrm{em}$ 1960 e chegando a 197 em 1970, mantidos até 1980. Nota-se que o número de municípios praticamente dobrou de novo entre 1960 e 1970. Chegou finalmente a 217 em 1991, o que foi um modesto acréscimo ao longo dessas últimas duas décadas. De qualquer forma, essa evolução mostra a necessidade de cuidar da homogeneização em comparações intertemporais de dados municipais, pois, pelo menos no número de municípios do Estado, teria havido um efeito mínimo da construção da rodovia BR-101.

Nos dados censitários de 1950 e de 1960, foram desconsiderados na Zona da Bacia do Itajaí, que pertence às Zonas ou Microrregiões do Litoral, os municípios de Ibirama, Ituporanga, Presidente Getúlio, Pouso Redondo, Rio do Oeste, Rio do Sul, Taió e Trombudo Central, mas incluídos na Zona do Planalto de Canoinhas, em 1950, e na Zona de Canoinhas, em 1960, que pertencem às Zonas ou Microrregiões do Interior. 
Nos censos de 1970 e 1980, o município de Alfredo Wagner não foi considerado na microrregião Colonial Serrana Catarinense, que pertence à região das Zonas ou Microrregiões do Litoral, passando a integrar a microrregião dos Campos de Lages nas Zonas ou Microrregiões do Interior. Em 1991, o município de Alfredo Wagner, agora na microrregião do Tabuleiro, pertencente à região do Litoral, foi incluído na microrregião dos Campos de Lages, no Interior.

Por outro lado, não foram considerados no Interior, os dados referentes aos municípios de Presidente Nereu, da microrregião de Rio do Sul, e Vidal Ramos, da microrregião de Ituporanga, mas incluídos nas microrregiões de Blumenau e Tijucas, respectivamente, ambas do Litoral.

Por fim, a investigação das migrações abrangeu aspectos como população rural e urbana $^{4}$ e número de pessoas não naturais do município onde residem, segundo a Unidade Federativa do domicílio anterior. Essas pessoas não naturais do município de sua residência, como designadas pelo IBGE nos censos, são referidas a seguir como "imigrantes", a fim de dar mais fluidez ao texto.

\section{Litoralização}

A distribuição espacial da população de Santa Catarina alterou-se significativamente entre 1950 e 1991. Além disso, esse fenômeno ocorreu conjuntamente com o crescimento populacional nas duas grandes regiões definidas acima, crescimento esse que também ocorreu no país como um todo. A Tabela 1 resume os totais populacionais relevantes, já incluindo informação sobre a população rural e urbana de cada região para fins de análise mais à frente.

\footnotetext{
${ }^{4}$ A definição de domicílio urbano, usada pelo IBGE, tende a superestimar as áreas urbanas em regiões de atividade predominantemente agrícola, especialmente no sul do Brasil (VEIGA, 2008).
} 
Tabela 1 - População total, segundo a situação do domicílio do Brasil, de Santa Catarina e das Zonas ou Microrregiões do Litoral e do Interior - 1950 a 1991

\begin{tabular}{l|r|r|r|r|r}
\hline $\begin{array}{c}\text { Região / Situação } \\
\text { do Domicílio }\end{array}$ & \multicolumn{1}{c|}{1950} & \multicolumn{1}{c|}{1960} & \multicolumn{1}{c|}{1970} & \multicolumn{1}{c}{1980} & \multicolumn{1}{c}{1991} \\
\hline Brasil & 51.944 .397 & 70.191 .370 & 93.139 .037 & 119.002 .706 & 146.825 .475 \\
\hline Urbana & 18.782 .891 & 31.533 .681 & 52.084 .984 & 80.436 .409 & 110.990 .990 \\
\hline Rural & 33.161 .506 & 38.657 .689 & 41.054 .053 & 38.566 .297 & 35.834 .485 \\
\hline Santa Catarina & 1.560 .502 & 2.129 .252 & 2.901 .734 & 3.627 .933 & 4.541 .994 \\
\hline Urbana & 362.717 & 688.358 & 1.246 .043 & 2.154 .250 & 3.208 .537 \\
\hline Rural & 1.197 .785 & 1.440 .894 & 1.655 .691 & 1.474 .042 & 1.333 .457 \\
\hline Litoral & 831.898 & 1.088 .072 & 1.448 .158 & 1.894 .848 & 2.582 .077 \\
\hline Urbana & 242.853 & 440.328 & 791.242 & 1.377 .035 & 2.091 .857 \\
\hline Rural & 589.045 & 647.744 & 656.916 & 517.813 & 490.220 \\
\hline Interior & 728.604 & 1.041 .180 & 1.453 .576 & 1.733 .085 & 1.959 .917 \\
\hline Urbana & 119.864 & 248.030 & 454.801 & 777.203 & 1.116 .680 \\
\hline Rural & 608.740 & 793.150 & 998.775 & 955.882 & 843.237 \\
\hline
\end{tabular}

Fonte: IBGE, Censos Demográficos de 1950, 1960, 1970, 1980 e 1991

O total da população, tanto de Santa Catarina como do Brasil, seguiu uma trajetória relativa similar, conforme ilustrado pelas linhas de números índices no gráfico da Figura 2. Isso significa que as taxas de crescimento foram bastante próximas. Entre 1950 e 1991, as populações totais do Brasil e de Santa Catarina cresceram a taxas médias anuais iguais, de 2,6\% ao ano (a.a.), quando arredondadas para um dígito decimal.

Já quanto às duas regiões definidas para o estudo, a evolução é diferente, ainda conforme o gráfico da Figura 2. A trajetória relativa do Litoral e do Interior estão próximas até 1970, embora a população total do Litoral tenha crescido menos, 2,8\% a.a., em comparação com o Interior, 3,5\% a.a. Já a partir de 1970, até 1991, o Interior, com crescimento de 1,4\% a.a., fica para trás do Litoral, este com o dobro do crescimento, 2,8\% a.a. Claramente a trajetória da população total do Litoral distancia-se em termos relativos. Isso é consistente com os valores absolutos da Tabela 1. 
Figura 2 - Índice da população total do Brasil, de Santa Catarina e das Litoral e Interior de SC -1950 a 1991

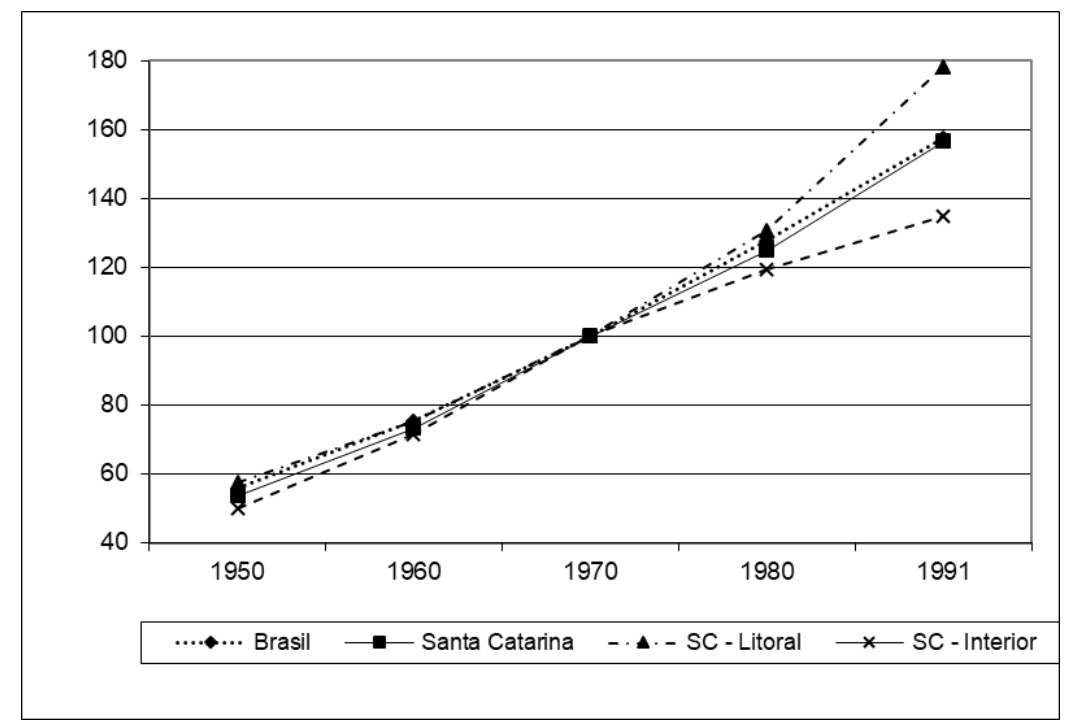

Obs.: base $1970=100$

Fonte: dados da Tabela 1, processados

Visto de modo alternativo, a participação do Litoral no total do Estado é levemente decrescente de 1950 até 1970, quando fica em 50\%, conforme ilustrado pelo gráfico da Figura 3. Contudo, no período posterior o Litoral aumenta sua participação até atingir 57\% em 1991. Esse resultado é consistente com a possível atração de migrantes após a inauguração da rodovia BR-101 e com o amadurecimento de seus efeitos diretos e indiretos, que aparentemente ocorreram nas décadas seguintes, revertendo a tendência de interiorização que avançava até 1970.

Figura 3 - Distribuição da população catarinense, segundo as Zonas ou Microrregiões do Litoral e do Interior - 1950 a 1991

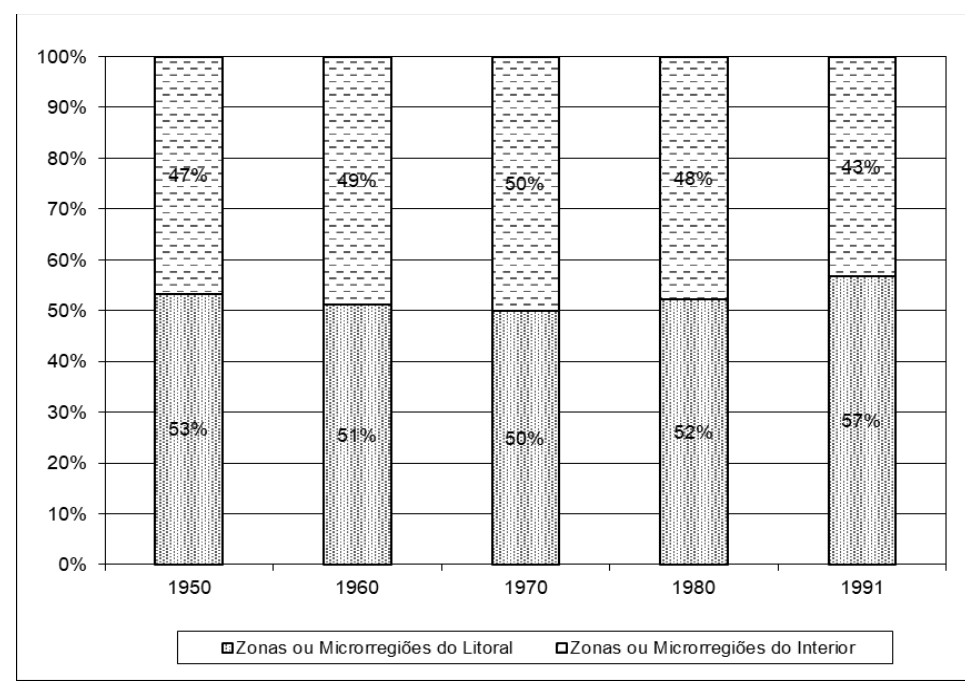

Fonte: dados da Tabela 1, processados 
Vários outros fatores podem também ter influenciado esse resultado, como já discutido na introdução, e estudos mais aprofundados seriam necessários para testar diferentes hipóteses. O que se pretende explorar em seguida são os fluxos migratórios associados a essa litoralização.

\section{Migração}

Uma região pode aumentar sua população tanto pela maior natalidade e menor mortalidade quanto pela maior imigração líquida. A informação sobre quem imigrou para um dado município é obtida por meio das perguntas censitárias sobre se a pessoa nasceu no município e sobre a unidade da federação de residência anterior. Contudo, as perguntas não captam diretamente o número dos que emigraram daquele município, o que se obtém via tabelas especiais a partir dos microdados censitários com as informações dos demais Estados. Para cada uma das regiões da presente análise, foi apenas possível distinguir entre os imigrantes provindos de Santa Catarina e os provindos de outros Estados.

O objetivo da análise desta seção é medir a presença de imigrantes no Estado, contrastando-se, segundo as duas regiões, Interior e Litoral, o antes e o depois da inauguração da BR-101. A hipótese é que houve aumento da migração do Interior para o Litoral após 1970.

À primeira vista, a Tabela 2 mostra um significativo crescimento no número de imigrantes não só em Santa Catarina, mas também no país como um todo. Para o Brasil, entre os censos de 1960 e de 1991, houve um crescimento médio no número de imigrantes de 4,2\% a.a., enquanto que em Santa Catarina o crescimento foi de 5\% a.a. Nos 31 anos considerados nessa tabela, o número de imigrantes aproximadamente quadruplicou, pouco abaixo para o Brasil e pouco acima para Santa Catarina.

Mesmo assim, a participação dos imigrantes na população total do Estado de Santa Catarina foi menor do que na média do país durante todo o período de 1960 a 1991, como ilustrado pelo gráfico da Figura 4. No entanto, a diferença dessa participação diminuiu consideravelmente entre o início e o final do período, iniciando com seis pontos percentuais (p.p.) e terminando com menos do que um p.p. 
Tabela 2 - Número e taxa de crescimento anual de imigrantes no Brasil, em Santa Catarina e nas Zonas ou Microrregiões do Litoral e do Interior, segundo o lugar do domicílio anterior 1960 a 1991

\begin{tabular}{|c|c|c|c|c|c|c|c|}
\hline \multirow{2}{*}{$\begin{array}{l}\text { Região e lugar do } \\
\text { domicílio anterior }\end{array}$} & \multicolumn{4}{|c|}{ Número de imigrantes } & \multicolumn{3}{|c|}{ Taxa de crescimento anual } \\
\hline & 1960 & 1970 & 1980 & 1991 & $1960 / 1970$ & $1970 / 1980$ & $1980 / 1991$ \\
\hline Brasil & 21.804 .490 & 30.270 .451 & 54.273 .164 & 78.304 .610 & $3,3 \%$ & $6,0 \%$ & $3,4 \%$ \\
\hline Santa Catarina & 526.658 & 814.376 & 1.573 .803 & 2.393 .582 & $4,5 \%$ & $6,8 \%$ & $3,9 \%$ \\
\hline $\begin{array}{l}\text { Zonas ou Microrregiões } \\
\text { do Litoral }\end{array}$ & 171.786 & 308.244 & 730.428 & 1.249 .858 & $6,0 \%$ & $9,0 \%$ & $5,0 \%$ \\
\hline Santa Catarina & 152.608 & 273.364 & 607.241 & 963.121 & $6,0 \%$ & $8,3 \%$ & $4,3 \%$ \\
\hline Outras Unid. da Feder. & 19.178 & 34.880 & 123.187 & 286.737 & $6,2 \%$ & $13,4 \%$ & $8,0 \%$ \\
\hline $\begin{array}{l}\text { Zonas ou Microrregiões } \\
\text { do Interior }\end{array}$ & 354.872 & 506.132 & 843.375 & 1.143 .724 & $3,6 \%$ & $5,2 \%$ & $2,8 \%$ \\
\hline Santa Catarina & 156.924 & 258.127 & 484.952 & 700.204 & $5,1 \%$ & $6,5 \%$ & $3,4 \%$ \\
\hline Outras Unid. da Feder. & 197.948 & 248.005 & 358.423 & 443.520 & $2,3 \%$ & $3,8 \%$ & $2,0 \%$ \\
\hline
\end{tabular}

Fonte: IBGE, censos demográficos de 1960, 1970, 1980 e 1991

Figura 4 - Participação de imigrantes na população total do Brasil e de Santa Catarina 1960-1991

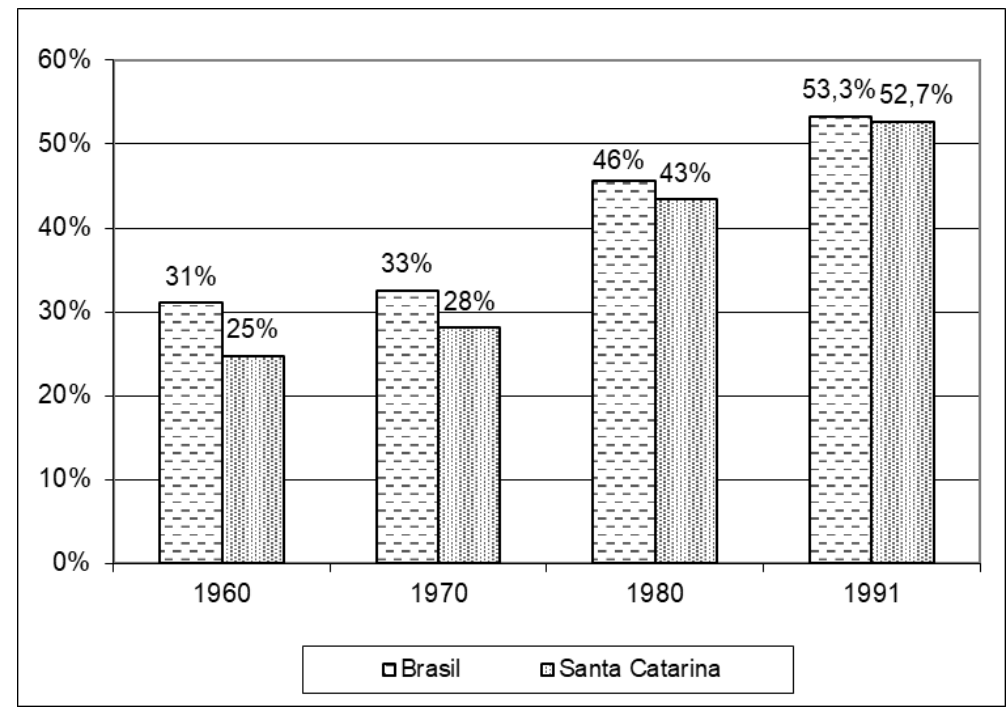

Fonte: dados das tabelas 1 e 2 , processados

Entre 1970 e 1980, no entanto, o crescimento do número de imigrantes foi significativamente maior do que nos outros períodos tanto para o Brasil, $6 \%$ a.a., quanto para Santa Catarina, 6,8\% a.a., conforme a Tabela 2. Portanto, na década da inauguração da BR-101 no trecho catarinense, o movimento imigratório acima da média foi, na verdade, um fenômeno nacional. É útil recordar que a construção da BR-101 afetou pouco mais do que a metade do litoral brasileiro, acompanhando uma ocupação espacial litorânea que tem sido uma característica brasileira desde seus primórdios. Portanto, é duvidoso que apenas a rodovia seja a principal explicação para tal movimento migratório nacional. Podemos recordar também o forte crescimento do PIB do Brasil naquela década, na verdade a última etapa da onda de 
crescimento iniciada ao final dos anos 1960 e conhecida como o período do milagre econômico. Para isolar o impacto apenas da BR-101 sobre os fluxos migratórios e sobre o crescimento do país, seria preciso, possivelmente, um estudo com metodologia diferente, dada a concentração prévia da população nas capitais litorâneas ao longo da BR-101 para muitos Estados da federação.

Restringindo-se a análise ao Estado de Santa Catarina, pode-se avaliar a relação entre a presença de imigrantes e a litoralização, mantendo controle dos períodos de antes e depois da inauguração da BR-101. Em termos de número de imigrantes, o Interior teve mais imigrantes nos quatro Censos reportados na Tabela 2. Portanto, não se pode dizer que o Interior foi esvaziado do ponto de vista populacional devido à emigração para o Litoral, mesmo porque o Interior teve crescimento substancial de sua população no período aqui analisado. $\mathrm{O}$ diferencial ocorreu, de fato, no ritmo de crescimento das respectivas imigrações, como se verá em seguida.

Os números totais de pessoas vindas de outras unidades da federação para o Interior foram maiores do que para o Litoral em cada Censo considerado, ainda conforme a Tabela 2. Contudo, para os imigrantes oriundos do próprio Estado isso só ocorreu no Censo de 1960. Logo, isso corrobora a hipótese da litoralização, apesar do reforço recebido pelo Interior de imigrantes de fora do Estado.

O Interior teve uma maior presença relativa de imigrantes em todo o período, conforme ilustrado pelo gráfico da Figura 5, porém o Litoral teve essa proporção convergindo para a do Interior. A mudança mais significativa ocorreu entre 1970 e 1980. Nessa década da inauguração da BR-101, o número de imigrantes cresceu 9\% a.a. no Litoral em contraste com os 5,2\% a.a. no Interior. Em contraste, na média das três décadas o crescimento do número de imigrantes foi de 6,6\% a.a. para o Litoral e de apenas 3,8\% a.a. para o Interior. Note-se que, mesmo assim, nessa década ocorreu a maior taxa de crescimento do número de imigrantes também para o Interior, em comparação com os outros períodos analisados. ${ }^{5}$ Isso é consistente com o observado paralelismo entre o crescimento migratório de Santa Catarina e do Brasil no período.

\footnotetext{
${ }^{5}$ Considerando-se os vários elementos que influenciam o crescimento populacional de uma região, que também incluem a natalidade e a mortalidade, a imigração teve forte influência. Mas é preciso lembrar que uma análise mais completa, com os dados dessas outras variáveis, seria necessária para discriminar a influência relativa de cada um desses elementos, o que não foi objeto da pesquisa reportada neste artigo.
} 
Figura 5 - Participação de imigrantes na população total de cada região de Santa Catarina - 1960-1991

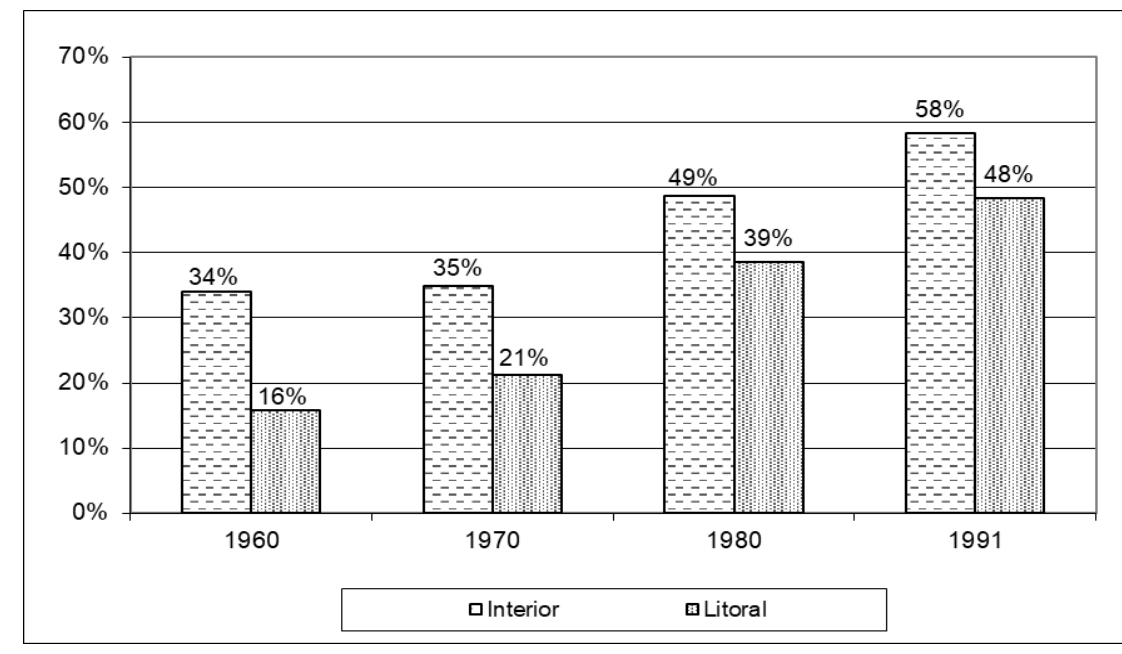

Fonte: dados das tabelas 1 e 2 , processados

Uma desagregação útil ao presente estudo é a do lugar de residência anterior do imigrante, se em outro município de Santa Catarina ou se em outra unidade da federação. Pela hipótese de que a BR-101 teve grande influência sobre a litoralização, espera-se que o principal contingente de imigrantes no Litoral tivesse vindo do próprio Estado, num movimento estimulado indiretamente pela rodovia.

Essa informação é apresentada em termos de participação de imigrantes de outros municípios de Santa Catarina no total de imigrantes de cada região da pesquisa. Como visto acima, a participação dos imigrantes no Litoral cresceu significativamente, convergindo para a mesma participação no Interior. Embora a participação dos imigrantes oriundos de Santa Catarina tenha sido maior no Litoral do que no Interior, nos quatro censos, como ilustrado pelo gráfico da Figura 6, a tendência de participação foi contrária ao esperado. Embora estável entre 1960 e 1970, a participação dos imigrantes de Santa Catarina no Litoral caiu em cada um dos dois censos seguintes. Isso equivale a dizer que aumentou a participação dos imigrantes de fora de Santa Catarina no Litoral nos censos de 1980 e 1991. Dito de outro modo ainda, a litoralização envolveu tanto a migração intraestadual como a interestadual, com a crescente participação do imigrante de outros Estados. 
Figura 6 - Participação de imigrantes de Santa Catarina no total de imigrantes, segundo as regiões de Santa Catarina - 1960-1991

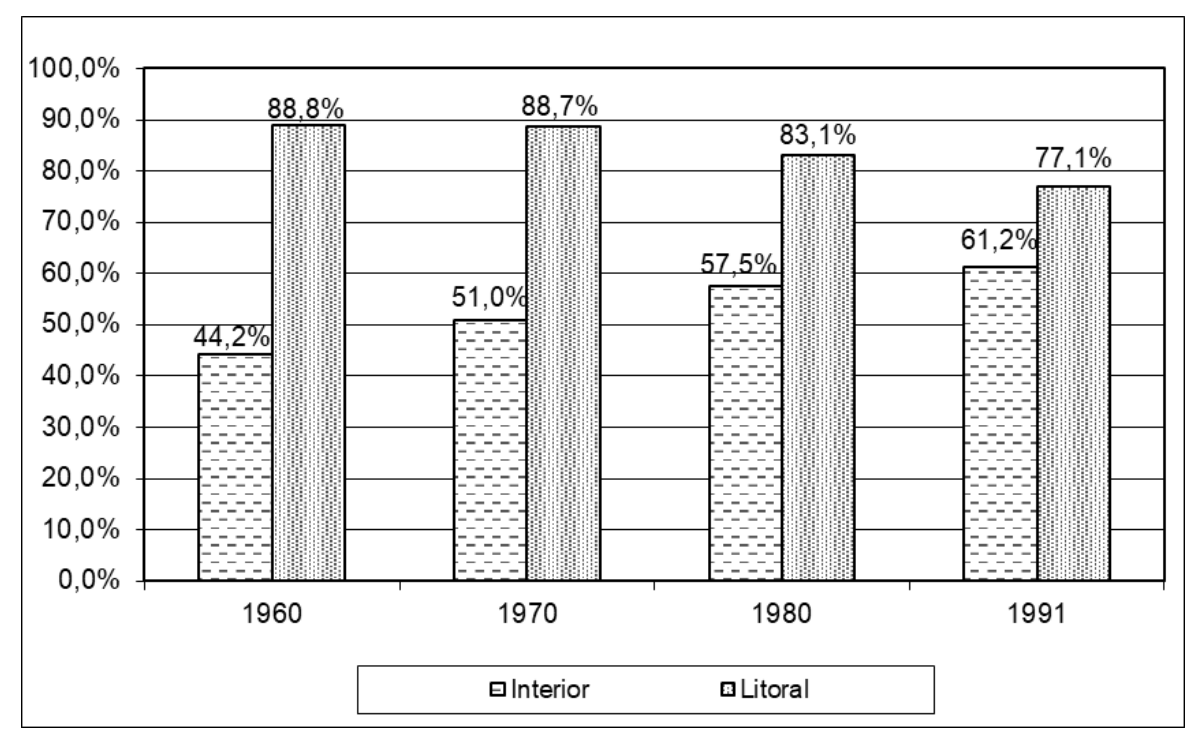

Fonte: dados da Tabela 2, processados

Cabe, ademais, estudar o saldo entre imigração e emigração interestadual de Santa Catarina. Um dos estudos que apresentam dados sobre emigração de Santa Catarina como um todo considera o período dos Censos de 1970 até o de 2000 (CUNHA; BAENINGER, 2005). Esse estudo informa as trocas migratórias, definidas como a diferença entre a variação do número de imigrantes de outras unidades da federação para Santa Catarina e dos emigrantes desse Estado, obtidos dos dados similares dos demais Estados. Entre 1970 e 1980, a troca migratória positiva foi muito pequena para Santa Catarina, com menos de três mil pessoas, mas entre 1980 e 1991 a diferença positiva aumentou significativamente, chegando a quase sessenta mil, e atingindo quase o triplo disso em 2000. No mesmo período, observam-se trocas migratórias negativas no Paraná e no Rio Grande do Sul entre 1970 e 1991.

Lima, Simões e Oliveira (2012) apresentam a matriz migratória interestadual para os censos de 1980 a 2010. Definem como emigrante a pessoa de uma dada unidade da federação que residia, numa data fixa de cinco anos antes, em outra unidade da federação. Um extrato dos dados de 1980 e de 1991, do ponto de vista de Santa Catarina, é apresentado para os Estados mais importantes na Tabela 3. Nesses dois Censos, o Estado de Santa Catarina teve saldo total positivo, mais do que duplicando de um Censo para o outro, consistente com o estudo de Cunha e Beaninger (2005). Nota-se ainda que a maior emigração catarinense foi para o Paraná e para o Rio Grande do Sul, também os mais importantes na imigração. O saldo migratório com o Paraná foi negativo em 1980, mas de baixa magnitude. Tornou-se positivo e representou acima da metade do saldo do total para Santa Catarina em 1991. Já o Rio Grande do Sul, que representou um saldo até maior do que o saldo total de Santa Catarina em 1980, perdeu essa 
posição para o Paraná como fornecedor líquido de imigrantes para Santa Catarina em 1991, quase igualando São Paulo, este um pouco atrás.

Tabela 3 - Pessoas que migraram para, ou de, Santa Catarina - Censos de 1980 e 1991

\begin{tabular}{l|r|r|r|r|r|r}
\hline \multirow{2}{*}{$\begin{array}{c}\text { Unidade da } \\
\text { Federação }\end{array}$} & \multicolumn{3}{|c|}{1980} & \multicolumn{3}{c}{1991} \\
\cline { 2 - 7 } & Imigrante & Emigrante & Saldo & Imigrante & Emigrante & \multicolumn{1}{c}{ Saldo } \\
\hline Rio de Janeiro & 2.030 & 947 & 1.083 & 2.266 & 702 & 1.564 \\
\hline São Paulo & 3.782 & 2.830 & 952 & 7.542 & 3.498 & 4.044 \\
\hline Paraná & 15.442 & 15.832 & -390 & 26.681 & 16.046 & 10.635 \\
\hline Rio Grande do Sul & 17.126 & 8.931 & 8.195 & 17.698 & 13.055 & 4.643 \\
\hline Mato Grosso & 122 & 1.569 & -1.447 & 1.232 & 3.955 & -2.723 \\
\hline Outras & 2.005 & 3.357 & -1.352 & 4.642 & 4.430 & 212 \\
\hline \multicolumn{1}{c|}{ Total } & 40.507 & 33.466 & 7.041 & 60.061 & 41.686 & 18.375 \\
\hline
\end{tabular}

Fonte: Lima, Simões e Oliveira (2012), Tabelas A1 e A2, processado

Em resumo, o Interior perdeu participação em relação ao Litoral, especialmente após a inauguração da BR-101 em Santa Catarina, conforme visto na seção anterior, com maior ritmo entre 1970 e 1980. Mas isso não significou um movimento migratório apenas do Interior para o Litoral. Ambas as regiões receberam contingentes bastante significativos de migrantes de outras Unidades da Federação. No caso do Litoral, a importância desses migrantes foi crescente, embora com predomínio dos migrantes do próprio Estado, lembrando que a população do Interior continuou crescendo, mesmo que a taxas menores do que as do Litoral e do país. Outros estudos apresentam evidências compatíveis, com boa proporção dessa imigração para o Litoral tendo vindo dos Estados vizinhos do Sul. O que se pretende explorar em seguida são os efeitos dessa litoralização sobre o crescente grau de urbanização do país e do Estado, verificando seus diferenciais após a inauguração da BR-101.

\section{Grau de Urbanização}

Uma nova grande rodovia pode alterar o uso do espaço na região de seu entorno, no caso, o litoral catarinense. O reforço de atividades econômicas já importantes no Litoral e o reforço das que antes eram incipientes têm implicações sobre os fluxos migratórios, dependendo da intensidade de uso do trabalho em cada uma delas. Além disso, a região do Litoral já tendia a concentrar a atividade industrial e de serviços, normalmente localizadas em zonas urbanas. Destacavam-se os seguintes setores industriais: cerâmico de revestimento, eletro-metalmecânico, têxtil-vestuário, calçados e material plástico. ${ }^{6}$ Assim, a hipótese a ser verificada é

\footnotetext{
${ }^{6}$ Ver Goularti Fo. (2002), especialmente o cap.4, que trata do período 1960-1990.
} 
que a inauguração da BR-101 reforçou o ritmo de urbanização no Litoral, comparado ao do Interior.

Até 1960, o Brasil tinha uma população com domicílio urbano menor do que a rural, conforme ilustrado pelo gráfico da Figura 7. Em 1950, pouco mais de um terço das pessoas vivia em domicílios urbanos, ao passo que em 1991 essa proporção já atingira três quartos. A passagem pela composição meio a meio ocorreu entre 1960 e 1970. Em Santa Catarina, com grau de urbanização inferior ao do Brasil em todos os Censos considerados, a ultrapassagem pelo meio a meio ocorreu na década seguinte, justamente a da inauguração da BR-101. O grau de urbanização de Santa Catarina aproximou-se daquele do Brasil, com um aumento em p.p. maior entre 1970 e 1980. Dados dos censos demográficos posteriores mostram que a taxa de urbanização de Santa Catarina praticamente igualou a brasileira somente em 2010.

Figura 7 - Grau de urbanização, segundo Brasil e Santa Catarina - 1960-1991

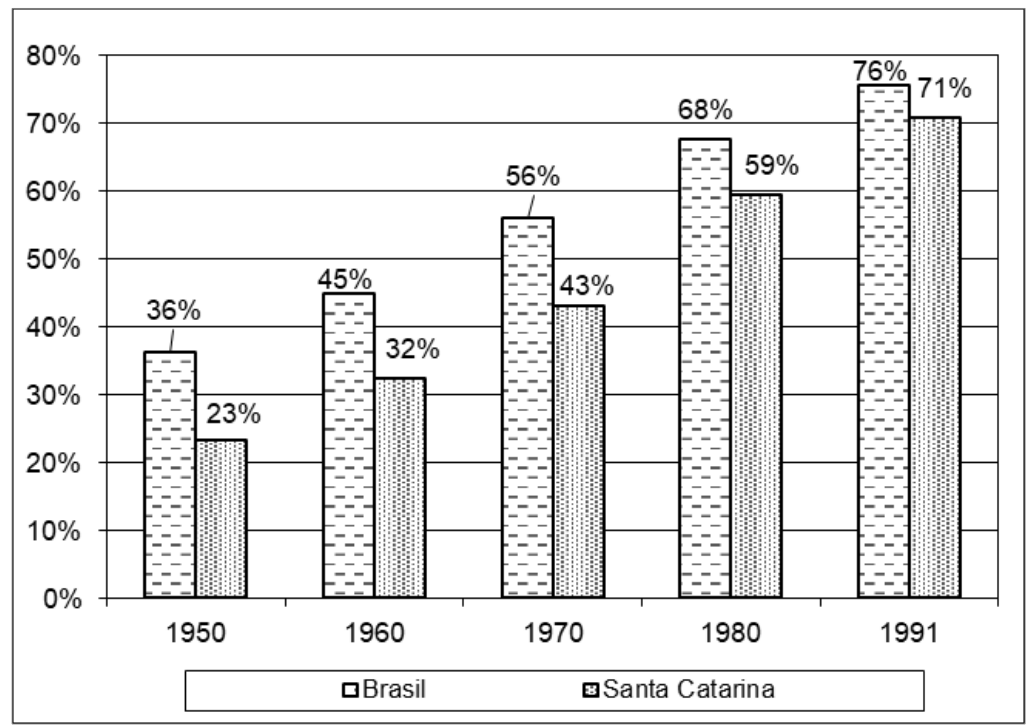

Fonte: dados da Tabela 1, processados

Qual teria sido a possível influência da construção da BR-101 sobre a evolução do grau de urbanização no Litoral de Santa Catarina no período de 1950 a 1991, assim como foi visto que parece ter tido influência na litoralização? Viu-se que, no caso do Brasil, o grau de urbanização superior a 50\% ocorreu entre 1960 e 1970, enquanto que para Santa Catarina, entre 1970 e 1980. Esse resultado é consistente com um possível impacto urbanizador da rodovia sobre o Estado, pois foi a partir dessa década que a participação da população do Litoral no total de Santa Catarina voltou a ficar acima dos 50\%, como ilustrado pelo gráfico da Figura 3.

O grau de urbanização do Litoral foi maior do que no Interior em todos os Censos, conforme o gráfico da Figura 8, como é de se esperar, uma vez que as atividades industrial e de 
serviços do Estado estão localizadas principalmente no Litoral desde as suas origens e, por sua natureza, tendem a ocupar zonas urbanas. Mas ambas as áreas tiveram um grau de urbanização crescente em todo o período. O Litoral ultrapassou 50\% de taxa de urbanização entre 1960 e 1970, enquanto que o Interior só o fez entre 1980 e 1991. Nesse último Censo, o Litoral de Santa Catarina atingiu um grau de urbanização maior que o do Brasil.

Figura 8 - Grau de urbanização, segundo as regiões de Santa Catarina - 1960-1991

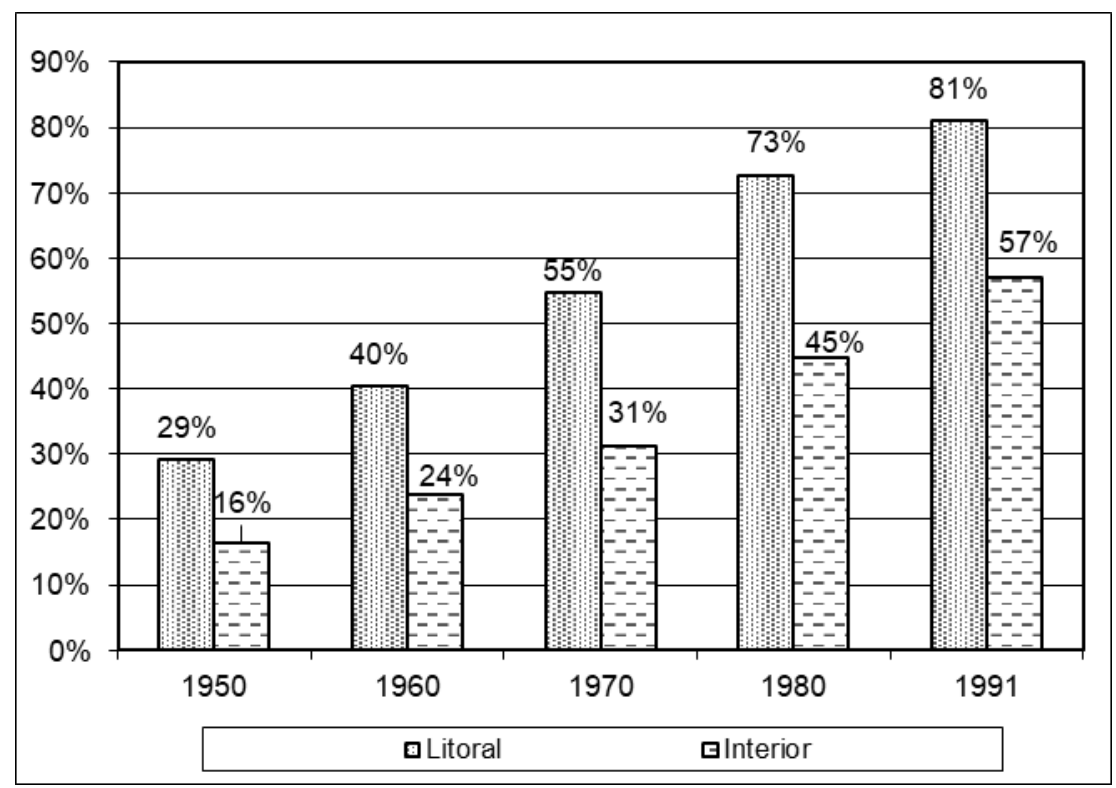

Fonte: dados da Tabela 1, processados

Apesar disso, o Interior teve taxas de crescimento da população urbana apenas um pouco abaixo das do Litoral em todo o período e até aproximou-se do Litoral entre os Censos de 1980 e 1991. Entre 1950 e 1991, a taxa de crescimento da população urbana do Litoral foi de 5,2\% a.a., ao passo que a correspondente taxa para o Interior foi de 5,0\% a.a., calculadas com base nos dados da Tabela 1. Restringindo o cálculo para o período entre 1970 e 1991, pós inauguração da rodovia, as taxas respectivas foram 4,7\% a.a. e 4,4\% a.a. Pode-se concluir que a hipótese de que a construção da BR-101 teria gerado uma maior taxa de urbanização no Litoral do que no Interior fica enfraquecida, mesmo considerando o fato de que, em todo o período, a taxa de urbanização do Litoral tenha sido sempre maior. Possivelmente, efeitos como a alteração da estrutura setorial, reforço e criação de atividades tanto no Litoral como no Interior, aqui por outras razões, possam ter se compensado, pouco alterando o ritmo de crescimento das populações urbanas das duas regiões do estudo. Exemplos disso são a forte expansão dos complexos agroindustriais da carne e da maçã. Aparentemente, ambas as regiões muito mais seguiram uma tendência nacional de urbanização do que foram influenciadas pela construção da rodovia. 


\section{Conclusão}

Verificou-se neste estudo que, entre 1950 e 1970, o Litoral vinha perdendo participação em relação ao Interior, embora esta região fosse maior. Elas atingiram iguais participações em 1970. Porém, após, o Litoral ganhou participação até atingir 57\% em 1991, o último Censo aqui considerado. A reversão de tendência a partir dos anos 1970 coincide com os possíveis efeitos de longo prazo de uma grande obra de infraestrutura como a BR-101 sobre fluxos migratórios, cuja inauguração no Estado de Santa Catarina ocorreu em 1971. Portanto, isso corrobora a hipótese de forte influência da construção da rodovia na migração para o litoral catarinense.

A outra hipótese que se buscou verificar foi que o crescimento relativamente maior do Litoral deve-se à migração do Interior. Na verdade, houve forte aumento simultâneo na proporção de imigrantes nas duas regiões, com ganhos maiores para o Litoral, já entre 1970 e 1980, continuando até 1991. Na média de Santa Catarina, essa trajetória do aumento da migração seguiu o país como um todo, o que enfraquece a possível influência da BR-101. Mas, em todo o período, houve crescente participação dos imigrantes de outras unidades da federação, destacando-se os oriundos do Paraná e do Rio Grande do Sul, os quais foram dominantes nas trocas migratórias catarinenses de 1980 em diante. Infelizmente, não se teve acesso a dados de 1970 para testar a hipótese de que esse movimento migratório sulista para Santa Catarina teve aumento significativo entre 1970 e 1980. Como é improvável que a rodovia tenha aumentado o crescimento populacional local do Litoral, o resultado inconclusivo das migrações, e conflitante com os dados de população total de cada região, talvez decorra da natureza dos dados. Trabalhou-se com dados a respeito da presença de imigrantes nas datas dos Censos, sem os saldos migratórios por região do estudo, o que pode distorcer os resultados.

O grau de urbanização foi maior no Litoral, iniciando com $29 \%$ em 1950, então menor do que a do Brasil, e chegando a $81 \%$ em 1991, já maior do que a taxa correspondente para o Brasil. Contudo, essa tendência já ocorria antes da inauguração da rodovia, de tal modo que o diferencial de ritmo de urbanização entre o Litoral e o Interior parece pouco significativo. Podese concluir que a BR-101 teve pouco impacto diferenciado sobre a evolução da taxa de urbanização nas duas regiões do estudo, rejeitando a hipótese inicial sobre isso. Mesmo assim, pode-se levantar a hipótese alternativa de que outros fatores podem ter tido influência no grau de urbanização do Interior e que precisariam ser controlados na análise. Com a metodologia do presente estudo não foi possível investigar isso.

Os principais diferenciais do estudo foram a construção de áreas homogêneas para fins da comparação intertemporal e uma avaliação do possível impacto da BR-101 sobre o fenômeno demográfico da litoralização de Santa Catarina. Entretanto, não se deve atribuir 
somente à construção dessa rodovia o aumento relativo da população no litoral do Estado. É também inegável a importância das transformações ocorridas nas regiões de origem dos migrantes, no caso de Santa Catarina os do Interior, em especial das zonas agrícolas do Oeste, bem como da atividade governamental de planejamento e de incentivos ao desenvolvimento econômico nas diferentes regiões do Estado. Isso possivelmente influenciou a dinâmica populacional observada durante o período posterior à inauguração da BR-101.

Por mais que uma grande rodovia gere externalidades numa área ampla e melhore a integração econômica de regiões em seu entorno, por si só ela não induz novas atividades econômicas em prazo razoável. Onde já existe um potencial de atividade econômica, pode ocorrer sua expansão após uma nova rodovia, desde que haja um mínimo de competitividade. Exemplos de rodovias que não tiveram o efeito desejado para uma dada região são a Transamazônica e a BR-116 no trecho catarinense. A Transamazônica foi um fracasso econômico dos anos 1970, amplamente conhecido. Já o impacto da BR-116 foi principalmente sobre o município de Lages, que teve um relativamente breve e próspero ciclo da madeira. A região do complexo mobiliário, no norte do Estado, cedo voltou-se para exportações, pouco dependendo dessa rodovia. Por sua vez, a BR-101 encontrou uma indústria e um potencial turístico disseminados praticamente em toda sua extensão no Estado.

\section{Referências}

BRASIL. Lei $\mathrm{n}^{\circ}$ 4.592, de 29 de dezembro de 1964 - Aprova o Plano Nacional de Viação (PNV). DOFC, Brasília, DF, 31 dez. 1964. Obtido em: http://tinyurl.com/zkuwxho. Acesso em: 28/10/2017. BRASIL. Ministério dos Transportes. Departamento Nacional de Infraestrutura de Transportes. Mapa rodoviário - Santa Catarina. Brasília, DF, 2002.

CRAICE, C.; PEZZO, T. A dinâmica demográfica de Santa Catarina no período pós-1991. Revista NECAT, Ano 4, n. 7, p. 38-54, jan.-jun. 2015.

CUNHA, J. M. P.; BAENINGER, R. Cenários da migração no Brasil nos anos 90. Caderno CRH, v. 18, n. 43 , p. 87-101, 2005.

DENG, T. Impacts of transport infrastructure on productivity and economic growth: recent advances and research challenges. Transport Reviews, v. 33, n. 6, p. 686-699, 2013.

ELBURZ, Z.; NIJKAMP, P.; PELS, E. Public infrastructure and regional growth: lessons from metaanalysis. Journal of Transport Geography, v. 58, p. 1-8, 2017.

GOULARTI F $^{\circ}$, A. Formação econômica de Santa Catarina. Florianópolis: Cidade Futura, 2002.

IBGE. Censo demográfico: Estado de Santa Catarina. Rio de Janeiro: IBGE, 1955. 131 p. (Recenseamento geral do Brasil 1950, 6. Série Regional, v. 27, t. 1).

IBGE. Censo demográfico. Rio de Janeiro: IBGE, 1956. 354 p. (Série Nacional, v. 1).

IBGE. Atlas geográfico de Santa Catarina. Rio de Janeiro: IBGE, 1958. s. 2, publ. 2.

IBGE. Censo demográfico de 1960: Brasil. Rio de Janeiro: IBGE, 1962. 177 p. (Recenseamento geral do Brasil, 7. Série Nacional, v. 1).

IBGE. Censo demográfico de 1960: Santa Catarina. Rio de Janeiro: IBGE, 1962(a). 178 p. (Recenseamento geral do Brasil, 7. Série Regional, v. 1, t. 15, $1^{\mathrm{a}}$ parte).

IBGE. Censo demográfico de 1960: Santa Catarina. Rio de Janeiro: IBGE, 1962(b). 168 p. (Recenseamento geral do Brasil, 7. Série Regional, v. 1, t. 15, 2a parte).

IBGE. Censo demográfico: Brasil. Rio de Janeiro: IBGE, 1971(a). 331 p. (Recenseamento geral 1970, 8. Série Nacional, v. 1). 
IBGE. Censo demográfico: Santa Catarina. Rio de Janeiro: IBGE, 1971(b). 642 p. (Recenseamento geral 1970, 8. Série Regional, v. 1, t. 20).

IBGE. Censo demográfico: dados gerais: migração: instrução: fecundidade: mortalidade: Santa Catarina. Rio de Janeiro: IBGE, 1982. 427 p. (Recenseamento geral do Brasil 1980, 9. v. 1, t. 4, n. 21).

IBGE. Censo demográfico: dados gerais: migração: instrução: fecundidade: mortalidade: Brasil. Rio de Janeiro: IBGE, 1983. 267 p. (Recenseamento geral do Brasil 1980, 9. v. 1, t. 4, n. 1).

IBGE. Censo demográfico 1991: migração: resultados da amostra: Brasil. Rio de Janeiro: IBGE, 1991(a). n. 1, 367 p.

IBGE. Censo demográfico 1991: migração: resultados da amostra: Santa Catarina. Rio de Janeiro: IBGE, 1991(b). n. 23, 329 p.

IBGE. Censo demográfico 1991: resultados do universo relativos às características da população e dos domicílios: Brasil. Rio de Janeiro: IBGE, 1991(c). n. 1, 209 p.

IBGE. Censo demográfico 1991: resultados do universo relativos às características da população e dos domicílios: Santa Catarina. Rio de Janeiro: IBGE, 1991(d). n. 23, 363 p.

IBGE. Reflexões sobre os deslocamentos populacionais no Brasil. Rio de Janeiro: IBGE, 2011. Obtido em: http://tinyurl.com/gtu2g6c. Acesso em: 28/10/17.

LIMA, A. C. C.; SIMÕ̃S, R.; OLIVEIRA, A. M. H. C. Caracterização dos padrões migratórios brasileiros no período 1980-2010. In: XVIII ENCONTRO NACIONAL DE ESTUDOS POPULACIONAIS, nov. 2012, Águas de Lindoia, SP, ABEP. Anais ... Obtido em: http://abep.org.br/publicacoes/index.php/anais/issue/view/37/showToc. Acesso em: 28/10/17.

MIOTO, B. T. Movimentos migratórios em Santa Catarina no limiar do século XXI. 1997. 85 f. Trabalho de Conclusão de Curso (Graduação em Economia) - Universidade Federal de Santa Catarina, Florianópolis, 2008. Obtido em: http://tcc.bu.ufsc.br/Economia293384. Acesso em: 28/10/17.

PEREIRA, A. M.; ANDRAZ, J. M. On the economic effects of public infrastructure investment: a survey of the international evidence. Journal of Economic Development, v. 38, n. 4, p. 1, 2013.

SANTA CATARINA. Secretaria de Estado de Coordenação Geral e Planejamento. Subsecretaria de Estudos Geográficos e Estatísticos. Atlas Escolar de Santa Catarina. Rio de Janeiro: Aerofoto Cruzeiro, 1991.

VASQUES, S. A construção da BR-101 e seus reflexos na economia de Joinville. 2002. 56 f. Trabalho de Conclusão de Curso (Graduação em Economia) - Universidade Federal de Santa Catarina, Florianópolis, 2002. Obtido em: http://goo.gl/fKnPz3. Acesso em: 28/10/17.

VEIGA, J. E. Cidades imaginárias: o Brasil é menos urbano do que se supõe. In: THEIS, I. M. (Org.) Desenvolvimento e Território: questões teóricas, evidências empíricas. Santa Cruz do Sul: EDUNISC, 2008, p.69-101. 